\title{
ПОВЫШЕНИЕ ЭФФЕКТИВНОСТИ СИСТЕМЫ УПРАВЛЕНИЯ ДЕЛОВОЙ КАРЬЕРОЙ РАБОТНИКОВ
}

\section{IMPROVING THE EFFICIENCY OF THE BUSINESS CAREER MANAGEMENT SYSTEM}

\section{A. Ryzhova \\ T. Kurbatskaya}

Summary: This article is devoted to the issue of improving the efficiency of the business career management system. The article gives a brief description of the definition of "business career of an employee", discusses the main stages and tools for the formation of a business career. The main goal of the article is to compare generations $X, Y, Z$, $A$ and determine which tools to apply to each generation in order to improve the efficiency of the business career management system.

Keywords: business career management system, stages of a business career, elements of a business career, comparison of generations $X, Y, Z$, $A$, attitude to work of different generations.
$\Pi$ од управлением деловой карьерой работников организации понимается комплекс мероприятий по планированию, организации, мотивации и контролю служебного роста персонала с учетом целей, потребностей, возможностей, способностей и мотивации работника, а также исходя из целей, потребностей, возможностей и социально-экономических условий организации.

Основные способы формирования карьеры:

1) естественный - в данном варианте подготовка сотрудника происходит через комплекс должностных продвижений. Сотрудник приобретает опыт, работая в той или иной должности, и на базе полученного опыта появляется возможность освоить новые должностные функции. Естественным образом может быть подготовлен любой специалист, но такой способ не может дать ответ на вопрос, когда закончится подготовка специалистов и каково их будет количество;

2) искусственный - в данном случае предполагается целевая интенсивная подготовка. Данный способ формирования карьеры более результативен, поскольку проходит в заданные промежутки времени, однако высокое качество отнюдь не гарантировано. Преимущества данных способов объе-
Рыжова Анастасия Алексеевна

ФГАОУ ВО «Российский университет транспорта»

(Рут МИИТ), г. Москва

ryzhovaanastasiya1@gmail.com

Курбацкая Татьяна Борисовна

К.nсх.н., дочент, ФГАОУ ВО «Российский университет транспорта» (РУТМИИТ); Московский университет имени С.Ю. Витте, г. Москва

alterego123@yandex.ru

Аннотация: Данная статья посвящена вопросу повышения эффективности системы управления деловой карьерой. В статье дана краткая характеристика определению «деловая карьера работника», рассмотрены основные этапы и инструменты формирования деловой карьеры. Главная цель статьи - сравнить поколения X, Y, Z, A и определить, какие инструменты применять к каждому поколению, чтобы повысить эффективность системы управления деловой карьерой.

Ключевые слова: система управления деловой карьерой, этапы деловой карьеры, элементы деловой карьеры, сравнение поколений X, Y, Z, A, отношение к работе разных поколений.

диняет способ формирования карьеры по эталону. Этот способ предполагает горизонтальное и вертикальное перемещение работника, а в качестве эталона выступает некая схема профессионального роста и служебного продвижения, расписанная на ближайшие годы. Данная схема управления карьерой носит нормативный характер, но не всегда должным образом мотивирует сотрудников.

Одним из важнейших элементов управления карьерой является ее планирование, которое производится на базе программ управления карьерой. Программы управления карьерой должны содержать следующие составляющие:

1) конкретный детализированный учет должностей, которые могут быть вакантными;

2) индивидуальный подход к планированию карьеры специалиста на выдвижение;

3) стимулирование к повышению эффективности деятельности.

Когда планирование карьеры производится со стороны администрации, то оно выражается в форме схем замещения. Для оптимальной реализации карьерного плана схемы замещения дополняются индивидуальными планами карьеры. 
Таблица 1. Параметры карьерного продвижения представителей разных поколений

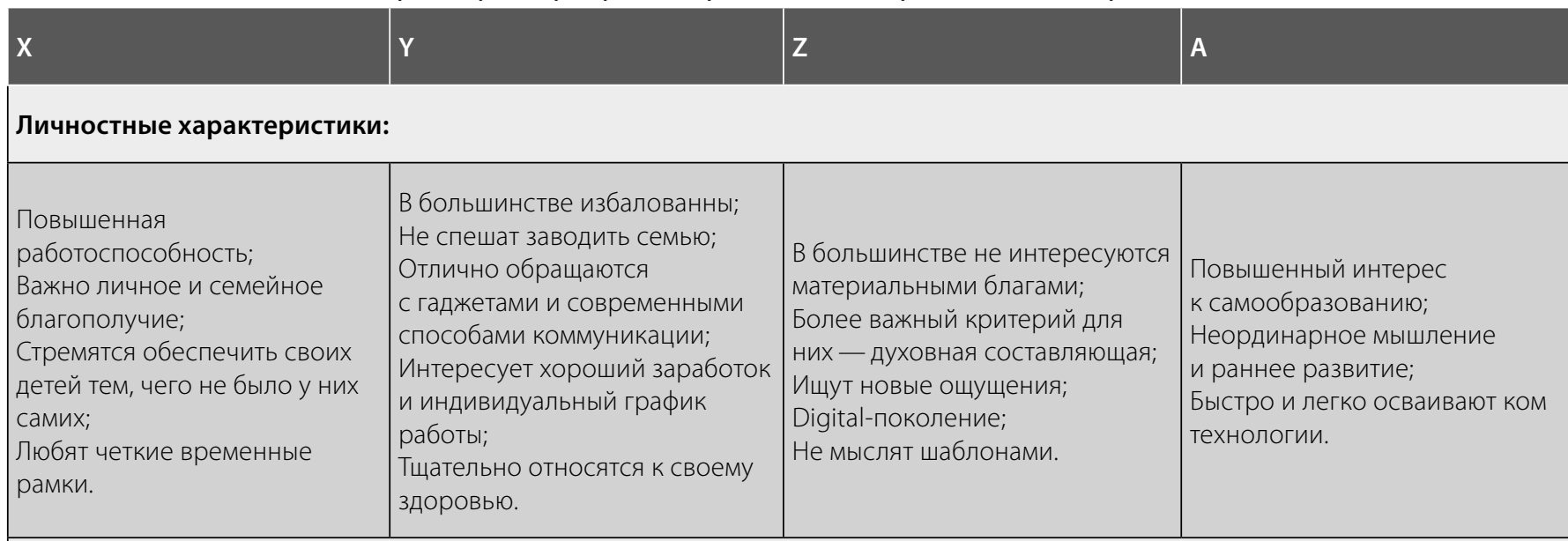

\section{Отношение к работе:}

Как правило постоянны; Боятся потерять работу; Активно продвигаются по карьерной лестнице.
Для них важно, чтобы работа

им нравилась, не будут

задерживаться если им

не нравится работа («гостинг»);

Легки на подъем, чаще всего

не боятся перемен;

Способны обрабатывать

большой объем информации;

Повышенная

работоспособность в условиях, которые комфортны ля них;

Любят неординарные задачи;

Предпочитают удалённую работ у или «гибкий график».
Предпочитают удаленную работу или «Гибкий график»; Не будут задерживаться если им не нравится работа («гостинг»); Могут моментально

переключаться с задачи на задачу;

Выполняют работу, проверяя себя на прочность;

Могут с легкостью взяться

за неизвестную им ранее

деятельность;

Лучше воспринимают

информацию визуально;

Любят «квесты».

\section{Специфика обучения:}

Больше подходит оффлайн обучение, непосредственно на производстве.
Можно совмещать онлайн и оффлайн обучение.
Можно совмещать онлайн и оффлайн обучение. Геймификация
Следующим важным элементом управления карьерой является отбор развивающей должности, что подразумевает должность, занятие которой поможет подготовить сотрудника к выполнению профессиональных обязанностей. Типовые схемы замещения разрабатываются с учетом выявленных взаимосвязей между требованиями к должностям. В таких схемах участвуют несколько должностей, которые связываются между собой «эффектом домино»: продвижение работника на открывшуюся вакантную должность создает вакансию в следующем звене такой цепочки, и т.д. Типовые схемы замещения обычно разрабатываются кадровой службой совместно с линейными руководителями. Сложности связаны с выстраиванием схемы замещения по всем должностям, поэтому в полном объеме работа по планированию схем замещения выполняется лишь по высшему звену управления - по группе ключевых должностей[1].

Управление карьерой тесно связано с формированием кадрового резерва, под которым подразумевается группа работников, которые специально отобраны из числа остальных сотрудников коллектива за счет достигнутых успехов в работе, для подготовки их к замещению ключевых должностей в организации.

При выборе работников для зачисления в кадровый резерв учитываются различные факторы: возраст, личный потенциал, степень мобильности, восприимчивость к обучению, творческие способности, характер подготовки, мотивация и т.д. 
Также одним из современных методов управления карьерой является система конкурентного замещения должностей. Ее суть заключается в том, что компания периодически озвучивает список достаточно «массовых» должностей, на которые объявляется конкурс. Претенденты допускаются к конкурсу, если подали заявку в отведенные сроки и по определенному формату. Плюсом данной процедуры является то, что заранее известны все желающие участвовать в конкурсе, и это является основой тщательного отбора. В данный момент в период пандемии претенденты на должность высылают свои документы и рассматриваются онлайн.

В последнее время на появились исследования в сфере взаимосвязи построения карьеры и управленческой ортобиотики. Управленческая ортобиотика, которая характерана для healthcare management (HM), что подразумевает высокую стрессоустойчивость, сильную волю и способность выдерживать большие физические и моральные нагрузки.

Суть всех инструментов и методов управления карьерой состоит в том, чтобы обеспечить мотивацию сотрудников к собственному развитию и занятию определенных должностей. Тем самым организация обеспечивает заполнение вакансий, отсутствие работников на которых чревато негативными последствиями[2].

Интересные результаты сравнения представителей различных поколений в отношении выстраивания деловой карьеры. Анализ результатов позволил нам составить приведенную ниже таблицу.

Анализируя таблицу, следует сказать, что четкой градации между поколениями нет, но у каждого поколения есть отличительные особенности, присущие только им. На основе этого, можно сделать выводы о том, какой подход использовать к каждому поколению, для эффективности управления их деловой карьерой.

1. Поколение $X$ не стоит давить отчетами, рамками и ограничениями. Обязательно давать поле для ответственности, для проведения в жизнь собственных решений. Необходимо давать возможность поддерживать баланс между работой и личной жизнью. Ставить новые задачи и сложные испытания. Планировать для них персональный карьерный путь. Также важно показывать им стабильность и уверенность в будущем. Реализовывать постоянное обучение. Для данного поколения важно иметь влияние на компанию.

Для данного поколения более подходят:

- Классические корпоративные тренинги;

Курсы;

- Соревнования (профессиональные конкурсы).
2. Поколение $Y$ лучше мотивировать новыми задачами, технологиям. Если есть возможность - рассматривать для них свободный или гибкий график работы и предоставлять возможность выбора форматов работы. Поколение $Y$ чувствует себя лучше при горизонтальных коммуникациях, но не стоит забывать о субординации. В работе с поколением Y очень важно ставить четкие цели с ограниченным сроком. Также им важна командная работа, но в данной работе им важно сохранять свою индивидуальность. Они очень хорошо ориентируются в работе, могут работать с большими объемами информации.

Для данного поколения более подходят:

- Обучение сериями;

- Творческая составляющая;

- Не использовать шаблонные задания;

- Обучение на стыке дисциплин.

3. Для поколения Z лучше всего походит мотивация позитивной, приятной рабочей атмосферой. Более продуктивны при гибком графике работы или при работе из дома. Возможность всегда быть в привычных каналах коммуникации, для них нет границ общения, в основном они одинаково общаются с людьми разных возрастов. Они достаточно трудолюбивые. Если четко знают какой результат должен быть, они работаю на тот результат, поэтому важна справедливая мотивация: соотношение «задачи-результат». Важно много хвалить, для них ценно, чтобы их потребности и интересы учитывались [3].

Для данного поколения более подходят:

- Не использовать соревнования, так как они болезненно переносят сравнения;

- Геймификация;

- Обучение с большим объемом визуализации.

4. Поколение А. Слишком рано говорить об их отношении к работе, так как данное поколение не старше 11 лет. Но оно очень развито, хорошо осведомлены в совсем не детских вопросах, их трудно заинтересовать, они стремятся к самопознанию и самообучению.

Конечно, приведенная классификация является весьма условными рамками. Много данные зависит от конкретной страны, региона и социальных условий, в которых живет человек. Вместе с тем, ориентиры помогают более четко выстроить мотивацию сотрудников разных возрастных категорий и вступать с ними в диалог. Поэтому, как было сказано выше, имеет смысл устоявшиеся способы разработки системы деловой карьеры сотрудников, использовать с учетом характеристик поколений. 


\section{ЛИТЕРАТУРА}

1. Абдуллина А.Д., Рабцевич, А.А. Управление карьерой работника в современных организациях / А.Д. Абдуллина, А.А. Рабцевич // Гуманитарные научные исследования. 2019. № 3 С. $87-89$

2. Абдулхаирова Э.М. Мотивация персонала через управление деловой карьерой / Э.М. Абдулхаирова// Символ науки. 2017. № 5. С. 75-76.

3. Электронный ресурс «Работа с сотрудникам разных поколений: X, Y, Z. 19.03.2020 г. URL: https://hr-elearning.ru/kak-rabotat-s-sotrudnikami-raznykhpokoleniy-хуz/ (дата обращения 10.07.2021 г.).

( Р Рыжова Анастасия Алексеевна ( ryzhovaanastasiya1@gmail.com ), Курбацкая Татьяна Борисовна ( alterego123@yandex.ru ). Журнал «Современная наука: актуальные проблемы теории и практики»

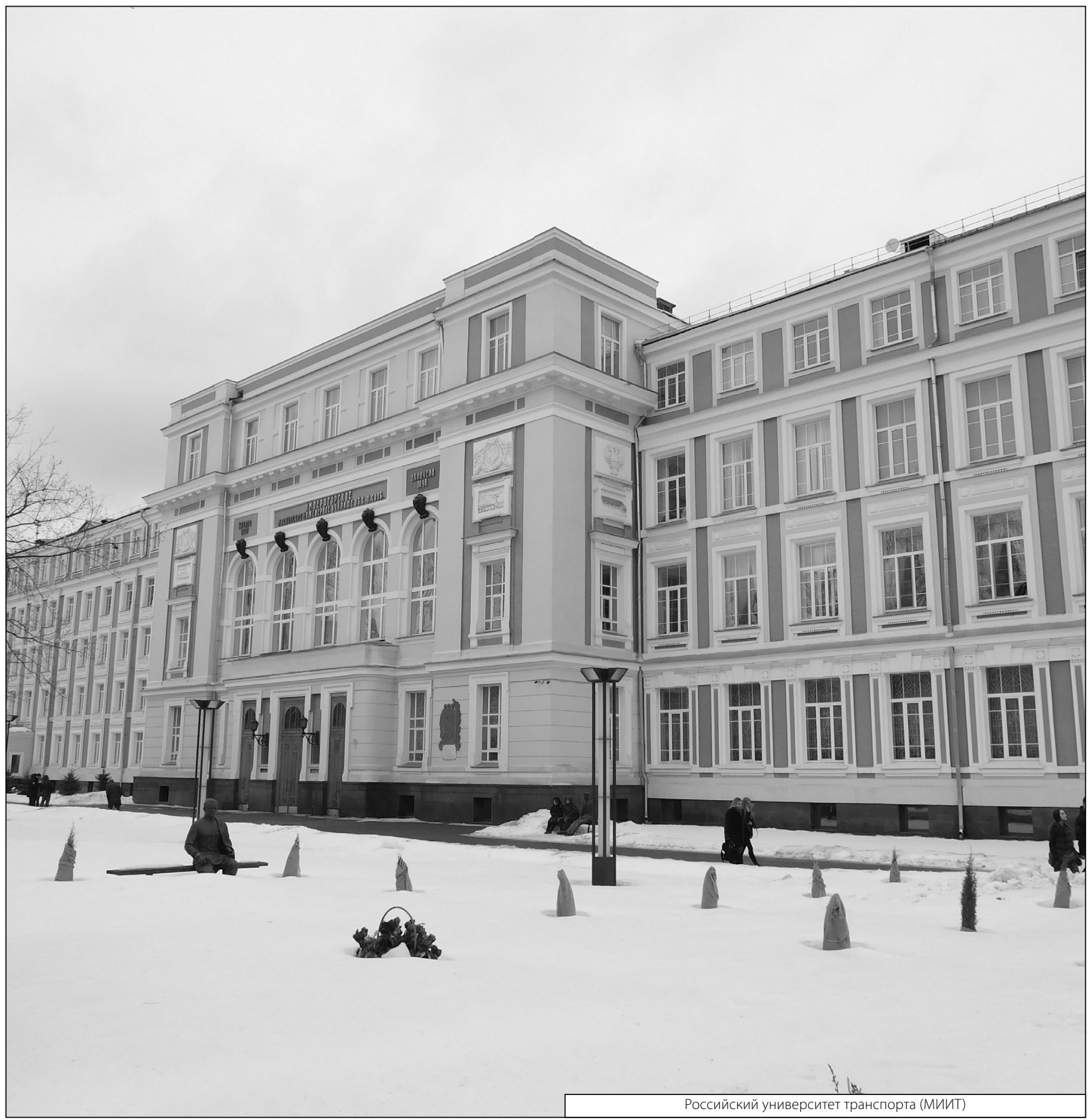

